Available Online at http://www.warse.org/IJETER/static/pdf/file/ijeter17782019.pdf https://doi.org/10.30534/ijeter/2019/17782019

\title{
Juxtaposition of Extant TV White Space Technologies for Long-Range Opportunistic Wireless Communications
}

\author{
Emmanuel Trinidad, Lawrence Materum \\ Department of Electronics and Communications Engineering, De La Salle University, Philippines \\ emmanuel_trinidad@dlsu.edu.ph
}

\begin{abstract}
Dynamic spectrum access (DSA) is one way to utilize and efficiently manage the frequency spectrum for wireless communications. One of DSA's implementation at the physical and medium access and controls layers through cognitive radio (CR). CR and other DSA methods at those layers offer better solutions for reaching and interconnecting users or things, especially those in the rural areas, including unconnected internet-of-things (IoT) devices. This work aims to survey current technologies and standards for DSA. In particular, the comparisons are those of unutilized bands that were allocated for television broadcasting, which is known as television white space (TVWS). The paper provides an overview of TVWS, its elements, different architecture depending on the chosen application, and to show potential gaps for future techniques and technologies for TVWS systems and research.
\end{abstract}

Key words: White Spaces, Dynamic Spectrum Access, Spectrum Management, Radio Spectrum, Frequency Allocation, Channel Allocation.

\section{INTRODUCTION}

Spectrum is a natural resource that enables us to communicate and exchange our data over wireless channels. The demand for higher capacity and data range exchange increases as the number of mobile and fixed broadband users also increases, thus congesting and limiting the availability of spectrum. This brings challenges for countries and operators of wireless communications to adapt and utilize every available spectrum efficiently. Thus, giving birth to cognitive Radio, the opportunistic manner of acquiring channels based on usage and location by the licensed frequency.

The transition from analog to digital of TV broadcasts 54 to $806 \mathrm{MHz}$, and the access and experimentation to the unlicensed frequency were headed by Federal Communications Commission (FCC) in November 2008 [1], draws a huge literature and research about utilizing these unlicensed frequencies. The Switchover has freed up a lot of space in many frequency bands thus paving way for Opportunistic or Cognitive Radio. These said frequencies between or the unused and unlicensed TV channels in the

Very high frequency (VHF) and Ultrahigh frequency (UHF) range also known as TV whitespace (TVWS). In present only 5 to $15 \%$ of the TV Spectrum is being used, this can be a good way to bridge the digital divide and connect the 3 Billion people still unconnected [2]. A lot of potential application opens up for these bands because of their good propagation characteristics. Advantages are as follows, the Non-Line of sight (NLOS) operation, large coverage area, obstacle penetration and lastly low cost in deployment.

Section 2 discusses its limitations, introducing the elements and methods in gaining TVWS while section 3 provides a brief classification of White space devices (WSD). Section 4 provides different standards by IEEE and others that support and promote TVWS to follow for the system design. Section 5 Provides a survey of available devices and companies. Section 6 related technology that can support the improvement of TVWS.

\section{ELEMENTS AND METHODS}

Advantageous as it may seem, there are certain limitations that need to be overcome before utilizing white spaces. There are still unresolved issues regarding the use of White Spaces and often they are restricted to regulatory requirements from different regulatory bodies nationally and globally. Enumerated as follows, protection of Primary users (PU) from interferences, transmit power of WSD including their operating parameters and antenna sizes.

One of the major problems in obtaining the spectrum is there should be no interference to the licensed or PU and the unknown Secondary users (SU) of the frequency. The protection of the licensed user or PUs should be the highest priority before gaining TVWS. Because of this, WSDs are required to be designed having a spectrum sensing feature. However, during the trials and testing with devices that has only spectrum sensing capability, it did not give the incumbents a confident result. This introduces us to the main element of the TVWS technology that differentiates TVWS from other wireless technologies, the White space database (WSDB). WSDB is a central database that contains all the information such as operating hours of the PUs, geographical operations, available channels to use and other operating parameters with respect to location. Geolocation is the capability of devices to gives its coordinates to the WSDB 
before providing the parameters for operating in TVWS for different zones as shown in table 1.

Table 1. Types of Zone Based on coexistence with TV Bands

\begin{tabular}{|c|c|}
\hline Location & Parameters \\
\hline Exclusion Zone & Active Transmitter not allowed \\
\hline Restriction Zone & Limited operating parameters \\
\hline Protection Zone & Defines Maximum allowed interference level \\
\hline
\end{tabular}

All of the WSD should query from the WSDB giving its current location and parameters to permit access of different WSD in the given location. These databases have the information of the occupied channels if it is currently in use by the incumbents or PUs in a certain location and is sometimes termed as a geo-location database. WSD will transmit its own location in order for the database to provide safe or unused frequency to use. See Figure 1 for a sample from a database of Network-Genetics for TVWS in Singapore approved by IDA.

The querying of WSD must follow a certain protocol that is applicable to all regulations, termed as Protocol to access whitespace or PAWS [3], that was released by the Internet Engineering Task Force (IETF). This standard requires devices to follow these steps: Database discovery, initialization, device registration, available spectrum query, spectrum use notification, and finally device validation. Another method of acquiring a safe spectrum to use is the Beaconing method. In this method, PUs tend to send a go signal to WSD to approve the use of its frequency spectrum, but this method requires the PU to modify also their parameters that is why it is not very practical to use this method.

Compactness or portability is a requirement for devices nowadays since WIFI and LTE are operating in a higher frequency, their antenna design is smaller. Utilizing the unlicensed TV bands poses a major problem for antenna design since the operations depend on what frequency is available for use. In practice the VHF band is rarely used as we can see later on in the WSDs table, most of the manufactured devices do not operate on the said bands due to antenna size with respect to the frequency used.

\section{DEVICE CLASSIFICATION}

Due to stringent protocols and features that WSD must obey, regulators proposed a hierarchy or classification of devices to lessen their complexity and cost, thus identifying the role of each device in the network.

Devices are classified into Type A for Fixed use with external or dedicated antenna, while Type B is for mobile use that is required to have a dedicated antenna. Fixed, Portable Devices with Mode II and Mode I, and finally a device that FCC only supports is the sensing-only device. Depending on the type of device, each has a certain method of operation. Fixed and Mode II devices can access and query with the WSDB while Mode I devices should be under the permission of a Fixed or Mode II device like a MasterSlave Configuration (United Kingdom's Ofcomm Regulations). Devices can also be categorized as Geolocation database (GDD) enabling or dependent for 802.11af Standard [4] same with Master-Slave type convention. Interference from PU must be observed, hence the standard operating parameters for every type of device was made. Comparisons of different regulations and standards for WSD can be found in [5]. For other countries such as New Zealand, they categorize their WSDs as Fixed, Base Station and Mobile, with the same analogy as the aforementioned devices. There are different naming conventions for each regulation, but more importantly, their parameters and operations are mostly alike.

Table 2: Classification of Devices and their Operating Parameters

\begin{tabular}{|l|l|l|l|}
\hline \multirow{2}{*}{ Type } & \multicolumn{2}{|l|}{$\begin{array}{l}\text { Maximum Operating Power Relative } \\
\text { to distance with PU Channel (EIRP) }\end{array}$} & $\begin{array}{l}\text { Available } \\
\text { Channel } \\
\text { Discovery }\end{array}$ \\
\cline { 2 - 3 } & Adjacent & Non-Adjacent & From WSDB \\
\hline Fixed & Not Allowed & $4 \mathrm{~W}$ EIRP & From WSDB \\
\hline MODE II & $40 \mathrm{~mW}$ & $100 \mathrm{~mW}$ & Fixed/Mode II \\
\hline MODE I & $40 \mathrm{~mW}$ & $100 \mathrm{~mW}$ & \multicolumn{2}{|l}{} \\
\hline
\end{tabular}

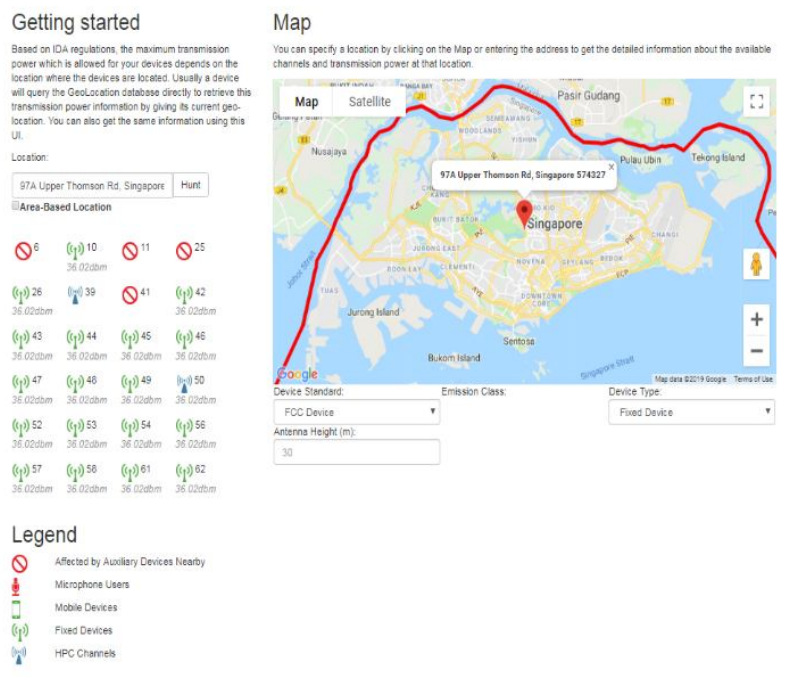

Figure 1: A sample of the geolocation database on the web provided by Network-Genetics.[6]

\section{STANDARDS}

When the spectrum band is successfully obtained without interference with the TV broadcast and wireless microphones, one should think of how it will not interfere with other TV whitespace users and what will be the appropriate wireless architecture depending on the application chosen. This section summarizes the standards and how they will be used architecturally. Different Standards by IEEE are developed to support, regulate, and harmonize the use of white spaces. 
IEEE 802.22 is a standard for by IEEE for Wireless regional area network (WRAN). This standard and architecture can be used for long-range communication as seen in figure 2 to provide broadband services for rural or remote areas up to $100 \mathrm{~km}$ that cannot be covered by existing infrastructure via fiber, XDSL or mobile communications. This provides a solution for Internet service providers (ISP) in wireless communications and can be a middle or last-mile solution.

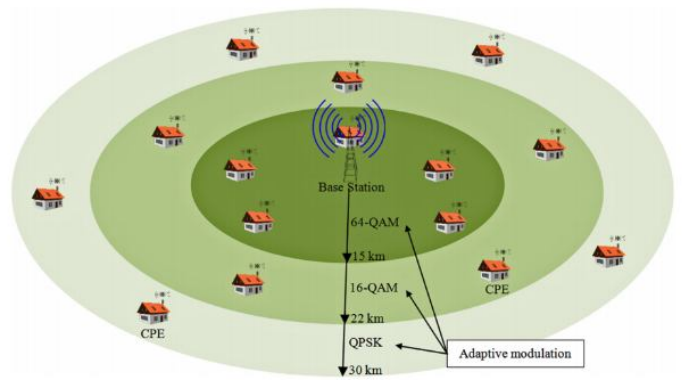

Figure 2: A Base Station Serving CPE based on 802.22 WRAN [5]

IEEE 802.11af is for Wireless local area network (WLAN), under these standards are the Wi-Fi Standards operating under $2.4 \mathrm{GHz}, 5 \mathrm{GHz}$, and $60 \mathrm{GHz}$. IEEE 802.11 af allows WIFI operations in TV bands in the MAC and PHY layers. It provides an alternative band for Wi-Fi that is already saturated in a Local Area Network. This standard introduces key elements in its architecture. First, the Geo-location database (GDB) equivalent to a WSDB, under it is the Registered location secure server (RLSS) that acts as a local database. Next, are the Geolocation database dependent (GDD) devices or entities, under these are the GDD enabling station ( Master Device) and GDD dependent device (Slave Device).

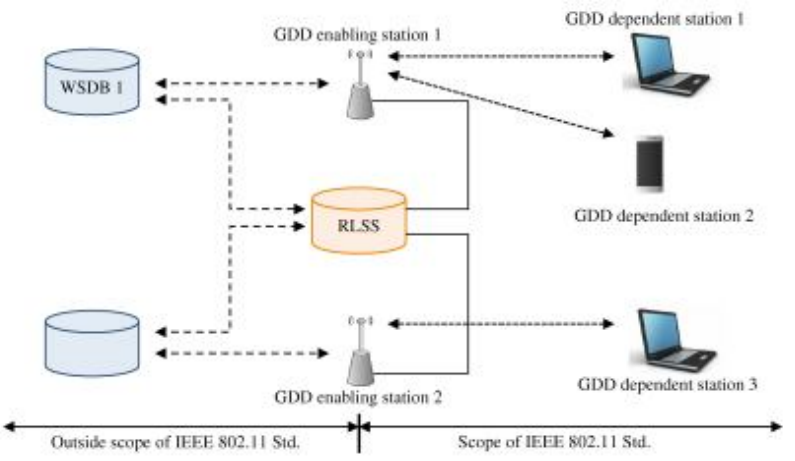

Figure 3: Architecture of 802.11af [5]

IEEE 802.15.4M standard is for Wireless personal area networks (WPAN). This standard is used by low power and low data rates of wireless devices, such as sensors. Just like in 802.11 af, 802.15.4m allows low power wireless devices to operate in the unlicensed TV bands. Due to good propagation and wide coverage, this can be a good application for the Internet of things (IoT) or machine to machine communication. TVWS bands give an advantage to this application because of its large coverage area with low power requirements.

Operating under the $1 \mathrm{GHz}$ band is favorable for many applications as it will increase transmission range. However, interfering with the PU is not the only concern, we must also consider sensing and detecting the $\mathrm{SU}$ and due to the increase of range capabilities, we may be interfering with other devices operating in the frequency band. For these purposes, IEEE 802.19.1 was developed for the coexistence of TVWS. The key elements of 802.19.1 are coexistence discovery and information server (CIDS), coexistence manager (CM), and the coexistence enabler (CE). The CIDS provides information about TVWS coexistence, while the CE acts as a mediator between incumbent users obtaining their information to coexist with them but does not directly interface a WSDB. The CM generates request or commands and control information to CE.

Table 3:. IEEE Standard Table for TVWS

\begin{tabular}{|l|l|l|}
\hline \multicolumn{2}{|c|}{ IEEE Standard } & Application \\
\hline 802.22 & WRAN & $\begin{array}{l}\text { Last-M ile Rural } \\
\text { Broadband }\end{array}$ \\
\hline $802.11 \mathrm{af}$ & WLAN & Super Wi-Fi, Hotspot \\
\hline $802.15 .4 \mathrm{~m}$ & WPAN & $\begin{array}{l}\text { Low Power M achine to } \\
\text { M achine }\end{array}$ \\
\hline & $\begin{array}{l}\text { coexistence } \\
\text { between }\end{array}$ & \\
802.19.1 & TVWS & Spectrum M anagement \\
\hline
\end{tabular}

Above standards in table 3 mainly modify the Medium access control (MAC) and the physical layer of the WSD, one notable standardization of devices operating in TVWS is the ECMA-392 can be found in [6].

Aside from the existing standards that support the use of TVWS, there are some developed open standards to promote its interoperability and usage. Weightless Org [7], provide three standards for IoT project, particularly the Weightless$\mathrm{W}$ is for the whitespace spectrum with 2-way directionality, a range of $5 \mathrm{~km}+$ with a long battery life of 3 to 5 years. This standard is for Low power wireless personal area network (LPWAN). Whitespace Alliance (WSA) promotes various standards to use in WhiteSpace Spectrum, like IEEE, $3^{\text {rd }}$ Generation Partnership Project (3GPP) and IETF. WSA has two open-access standards namely Wi-FAR that is based on IEEE 802.22 and enhances it to be added to OFDMA waveform. On the other hand, WSAConnect of WSA is derived from the IETF PAWS for interoperable specifications between WSDB and WSD. WSA supports its members for the success of using TVWS in the market in compliance with regulatory requirements [8]. 
Emmanuel Trinidad et al., International Journal of Emerging Trends in Engineering Research, 7(8), August 2019, 209 - 215

Table 4: WSD available in the market

\begin{tabular}{|c|c|c|c|c|c|c|c|c|c|}
\hline Device name & $\begin{array}{c}\text { Frequency } \\
\text { range }[\mathrm{MHz}]\end{array}$ & $\begin{array}{c}\text { Distance } \\
\text { covered } \\
{[\mathrm{km}]}\end{array}$ & Tx Power & $\begin{array}{c}\text { Max Data } \\
\text { Rate } \\
\text { (throughput) } \\
\text { with respect } \\
\text { to Channel } \\
\text { Bandwidth } \\
\end{array}$ & $\begin{array}{c}\text { Channel } \\
\text { Bandwidth }\end{array}$ & $\begin{array}{l}\text { Modulation } \\
\text { Scheme }\end{array}$ & $\begin{array}{l}\text { Topology } \\
\text { Supported }\end{array}$ & Regulation & Database \\
\hline $\begin{array}{c}\text { Saankhyalabs } \\
\text { Meghdoot Base } \\
\text { Station } \\
\text { SLB802ODU [9] }\end{array}$ & 400 to 700 & up to $20 \mathrm{~km}$ & $\begin{array}{c}30 \text { to } 36 \mathrm{dBm} \\
\text { EIRP }\end{array}$ & 19, $26 \mathrm{Mbps}$ & $\begin{array}{c}6 \mathrm{MHz} \text { and } 8 \\
\mathrm{MHz}\end{array}$ & $\begin{array}{l}\text { OFDMA, } \\
\text { QPSK, } 16 \\
\text { QAM, and } \\
\text { 64-QAM }\end{array}$ & $\begin{array}{l}\text { PTP and } \\
\text { PMP }\end{array}$ & $\begin{array}{c}\text { FCC/FCC } \\
\text { PART } 15 \\
\text { SUB-PART } \\
\text { H }\end{array}$ & Not Specified \\
\hline $\begin{array}{c}\text { Saankhyalabs } \\
\text { Dhaval CPE } \\
\text { Modem } \\
\text { SLC802ODU } \\
{[10]} \\
\end{array}$ & 400 to 700 & up to $20 \mathrm{~km}$ & $\begin{array}{l}30 \text { to } 36 \mathrm{dBm} \\
\text { EIRP }\end{array}$ & $19,26 \mathrm{Mbps}$ & $\begin{array}{c}6 \mathrm{MHz} \text { and } 8 \\
\mathrm{MHz}\end{array}$ & $\begin{array}{l}\text { OFDMA, } \\
\text { QPSK, 16 } \\
\text { QAM, and } \\
\text { 64-QAM }\end{array}$ & $\begin{array}{l}\text { PTP and } \\
\text { PMP }\end{array}$ & $\begin{array}{c}\text { FCC/FCC } \\
\text { PART } 15 \\
\text { SUB-PART } \\
\text { H }\end{array}$ & Not Specified \\
\hline $\begin{array}{c}\text { Adaptrum ACRS } \\
\text { 2.0 CPE [11] }\end{array}$ & 400 to 1000 & $\begin{array}{l}10 \mathrm{~km} \text { from } \\
\text { Base Station }\end{array}$ & $\begin{array}{c}100 \mathrm{~mW}(20 \\
\mathrm{dBm})\end{array}$ & $\begin{array}{c}13,20,24 \\
\text { Mbps }\end{array}$ & $6,8,10 \mathrm{MHz}$ & $\begin{array}{l}\text { QPSK, } \\
\text { 16QAM, } \\
\text { 64QAM, } \\
\text { 256QAM }\end{array}$ & N/A & $\begin{array}{c}\text { FCC Part15 } \\
\text { Subpart } \\
\text { H,ETSI } 301 \\
\text { 489-1, ETSI } \\
\text { EN } 301598 \\
\text { Singapore } \\
\text { IDA type } \\
\text { approval }\end{array}$ & $\begin{array}{c}\text { Nominet/Goo } \\
\text { gle/Iconectiv } \\
\text { e/Microsoft }\end{array}$ \\
\hline $\begin{array}{c}\text { Adaptrum } \\
\text { ACRS2 B1000 } \\
\text { (BASE } \\
\text { STATION) [12] }\end{array}$ & 400 to 1000 & $\begin{array}{c}10 \mathrm{~km}, 3 \\
\text { sectors } \\
\left(300 \mathrm{~km}^{\wedge} 2\right)\end{array}$ & $\begin{array}{l}600 \mathrm{~mW} \\
\text { conducted }\end{array}$ & $\begin{array}{l}13,20,24 \\
\text { Mbps }\end{array}$ & $6,8,10 \mathrm{MHz}$ & $\begin{array}{c}\text { QPSK, } \\
\text { 16QAM, } \\
\text { 64QAM, } \\
\text { 256QAM }\end{array}$ & $\begin{array}{l}\text { PTP and } \\
\text { PMP }\end{array}$ & $\begin{array}{l}\text { Approved } \\
\text { FCC, pending } \\
\text { ETSI, IDA }\end{array}$ & $\begin{array}{c}\text { Nominet/Goo } \\
\text { gle/Iconectiv } \\
\text { e/Microsoft }\end{array}$ \\
\hline $\begin{array}{c}\text { Adaptrum } \\
\text { ACRS2 B2000 } \\
\quad \text { (BASE } \\
\text { STATION) [13] }\end{array}$ & 400 to 1000 & $\begin{array}{c}10 \mathrm{~km}, 3 \\
\text { sectors } \\
\left(300 \mathrm{~km}^{\wedge} 2\right)\end{array}$ & $\begin{array}{c}200 \mathrm{~mW}(23 \\
\mathrm{dBm})\end{array}$ & $\begin{array}{c}23,34,42 \\
\text { Mbps }\end{array}$ & $\begin{array}{c}6,7,8, \text { dual } \\
\text { expansion } \\
\text { plan } 10 \mathrm{MHz} \\
\text { for } 6 \text { channel } \\
\text { plan }\end{array}$ & $\begin{array}{l}\text { QPSK, } \\
\text { 16QAM, } \\
\text { 64QAM, } \\
\text { 256QAM }\end{array}$ & $\begin{array}{l}\text { PTP and } \\
\text { PMP }\end{array}$ & $\begin{array}{l}\text { Pending: } \\
\text { FCC, ETSI, } \\
\text { IDA }\end{array}$ & $\begin{array}{c}\text { Nominet/Goo } \\
\text { gle/Iconectiv } \\
\text { e/Microsoft }\end{array}$ \\
\hline $\begin{array}{c}\text { 6Harmonics } \\
\text { GWS400 Series } \\
{[14]} \\
\end{array}$ & $470-698$ & $20 \mathrm{~km}$ & $23 \mathrm{dBm}$ & $33 \mathrm{Mbps}$ & $\begin{array}{c}6 \mathrm{MHz} \text { and } \\
\text { Dual channel } \\
12 \mathrm{MHz}\end{array}$ & $\begin{array}{l}\text { OFDM,from } \\
\text { BPSK to } 64 \\
\text { QAM }\end{array}$ & $\begin{array}{l}\text { PTP, PMP, or } \\
\text { Mesh }\end{array}$ & $\begin{array}{c}\text { FCC Part } 15 \\
\text { Subpart H }\end{array}$ & $\begin{array}{l}\text { SpectrumBrid } \\
\text { ge }\end{array}$ \\
\hline $\begin{array}{c}\text { KTS Wireless } \\
\text { AWR (Agility } \\
\text { White Space } \\
\text { Radio) }[15] \\
\end{array}$ & $470-698$ & Not Specified & $\begin{array}{l}10 \text { to } 21.5 \\
\text { dBm with } \\
\text { ATPC } \\
\end{array}$ & $\begin{array}{c}\text { 3.1 MBps or } \\
24 \mathrm{Mbps}\end{array}$ & $6 \mathrm{MHz}$ & SOQPSK & $\begin{array}{l}\text { PTP, PMP, or } \\
\text { Simplex }\end{array}$ & $\begin{array}{c}\text { FCC Part } 15 \\
\text { Subpart H }\end{array}$ & $\begin{array}{c}\text { SpectrumBrid } \\
\text { ge }\end{array}$ \\
\hline $\begin{array}{l}\text { Carlson Wireless } \\
\text { RuralConnect } \\
\text { Gen } 3 \text { ETSI [16] }\end{array}$ & $470-790$ & 10 to $40 \mathrm{~km}$ & $21 \mathrm{dBm}$ & $\begin{array}{c}96 \mathrm{Mbps} \\
\text { Aggregate }\end{array}$ & $8 \mathrm{MHz}$ & $\begin{array}{l}\text { QPSK, } \\
\text { 16QAM, } \\
\text { 64QAM, } \\
\text { 256QAM }\end{array}$ & $\begin{array}{c}\text { PTP } \\
\text { Backhaul }\end{array}$ & $\begin{array}{c}\text { FCC and } \\
\text { ETSI }\end{array}$ & $\begin{array}{c}\text { Telcordia } \\
\text { (now } \\
\text { iconectiv) } \\
\text { and } \\
\text { Spectrumbrid } \\
\text { ge }\end{array}$ \\
\hline $\begin{array}{c}\text { Carlson Wireless } \\
\text { RuralConnect } \\
\text { Gen } 3 \text { US [17] }\end{array}$ & $470-696$ & $10 \mathrm{TO}$ & $21 \mathrm{dBm}$ & $\begin{array}{c}72 \text { Mbps } \\
\text { Aggregate }\end{array}$ & $6 \mathrm{MHz}$ & $\begin{array}{l}\text { QPSK, } \\
\text { 16QAM, } \\
\text { 64QAM, } \\
\text { 256QAM }\end{array}$ & $\begin{array}{c}\text { PTP } \\
\text { Backhaul }\end{array}$ & $\begin{array}{c}\text { FCC and } \\
\text { ETSI }\end{array}$ & $\begin{array}{c}\text { Telcordia } \\
\text { (now } \\
\text { iconectiv) } \\
\text { and } \\
\text { Spectrumbrid } \\
\text { ge }\end{array}$ \\
\hline $\begin{array}{c}\text { Redline } \\
\text { Communications } \\
\text { Ellipse [18] }\end{array}$ & $470-698$ & $\max 100 \mathrm{~km}$ & $\operatorname{Max} 31 \mathrm{dBm}$ & $\begin{array}{l}\text { up to } 186.6 \\
\text { MbpsUBR }\end{array}$ & $\begin{array}{c}\text { Software } \\
\text { Selectable }\end{array}$ & $\begin{array}{c}\text { BPSK to } \\
\text { 256QAM 7/8 }\end{array}$ & $\begin{array}{l}\text { PTP and } \\
\text { PMP }\end{array}$ & $\begin{array}{c}\text { FCC Part } 15 \\
\text { Subpart H }\end{array}$ & Any \\
\hline $\begin{array}{c}\text { Aviacomm } \\
\text { ARF3010 [19] }\end{array}$ & 0.5 to 2800 & Not Specified & Up to $0 \mathrm{dBm}$ & Not Specified & $\begin{array}{c}\text { Software } \\
\text { Selectable }\end{array}$ & Not Specified & Not Specified & FCC & Not Specified \\
\hline $\begin{array}{c}\text { MetricSystems } \\
\text { (MSC) Raptor } \\
\text { XR [20] }\end{array}$ & $\begin{array}{c}174-216,470- \\
698 \\
\end{array}$ & Up to $40 \mathrm{~km}$ & $27.8 \mathrm{dBm}$ & $\begin{array}{c}12,25,31 \\
\text { Mbps } \\
\text { depending on } \\
\text { modulation }\end{array}$ & $6,7,8 \mathrm{MHz}$ & $\begin{array}{l}\text { QPSK, } \\
\text { 16QAM, } \\
\text { 64QAM }\end{array}$ & $\begin{array}{l}\text { PTP, PMP, or } \\
\text { Mesh }\end{array}$ & FCC & $\begin{array}{c}\text { Google/Spect } \\
\text { rumBridge }\end{array}$ \\
\hline $\begin{array}{c}\text { Whizpace } \\
\text { WhizRange [21] }\end{array}$ & $515-695$ & $\begin{array}{c}10 \mathrm{~km} \text { or } \\
\text { beyond }\end{array}$ & Not Specified & $\begin{array}{c}\text { 13.5 Mbps or } \\
54 \mathrm{Mbps} \\
\text { (with channel } \\
\text { bonding) }\end{array}$ & Not Specified & Not Specified & $\begin{array}{l}\text { PTP, PMP } \\
\text { (STAR) }\end{array}$ & $\begin{array}{l}\text { FCC and } \\
\text { IMDA }\end{array}$ & Not Specified \\
\hline $\begin{array}{c}\text { Whizpace } \\
\text { WhizMesh [21] }\end{array}$ & $515-695$ & $5 \mathrm{~km}$ & Not Specified & 16.25 Mbps & Not Specified & Not Specified & Mesh & $\begin{array}{l}\text { FCC and } \\
\text { IMDA }\end{array}$ & Not Specified \\
\hline
\end{tabular}

\section{RESULTS AND DISCUSSIONS}

As spectrum sharing grows, more companies have developed and provide WSDB services and WSD equipment. Services are now available in the market, Whizpace [2] for example offers network planning services up to implementations where TVWS is needed as a bridge to rural connectivity.
TVWS mainly relies on its WSDB to operate freely without interfering with the licensed users. Thus the arising of a lot of companies that provide a WSDB like Microsoft (see figure 4), Google, Neustar, Network-Genetics, and Nominet. 


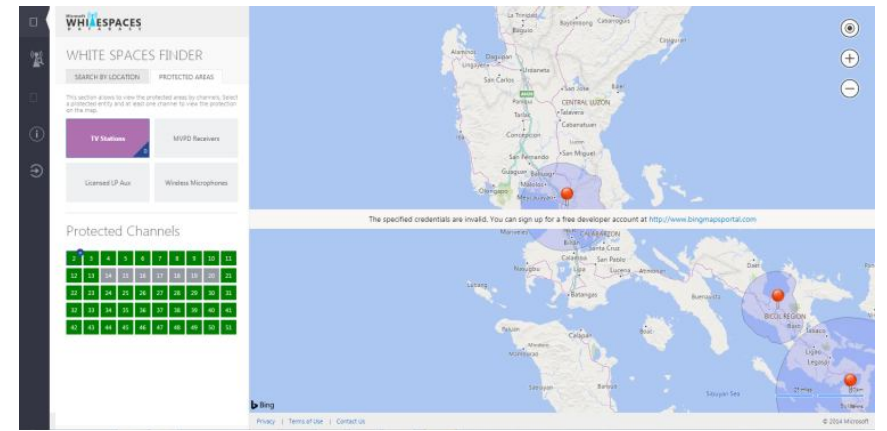

Figure 4: Microsoft Whitespace database showing protection zone from channel 2 in the Philippines [22]

WhiteSpace Devices has already been deployed and manufactured in some countries, in partnership with one of their ISPs, their main focus is providing rural broadband to act as a last-mile alternative for ISP to cover for the unreachable areas of their existing wireless or wired infrastructures. WSD provides a good solution with low complexity and costs in implementation. Different Topologies can be made with devices such as Point-to-Point (PTP), Point-to-Multipoint (PMP) or mesh for network needs and convenience. Table 4 shows the list of devices available in the market and their certain specifications. It is shown that most of the devices pass the FCC regulation which can be a basis for developers, network planner and regulatory bodies of other countries as a reference to follow. As seen in the table most of the frequency bands used are under the UHF band to provide compactness.

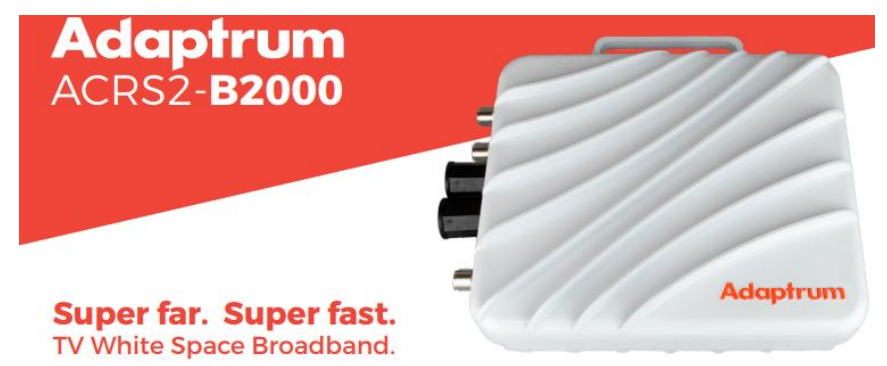

Figure 5: Adaptrum ACRS2-B2000 [13]

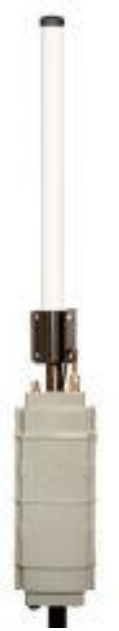

Figure 6: Saankhyalabs Meghdoot Base Station SLB802ODU[9]
Figure 5 and 6 shows the Adaptrum ACRS2-B2000 and Saankhyalabs Meghdoot SLB802ODU respectively as an example of a Base Station Device for TVWS technology.

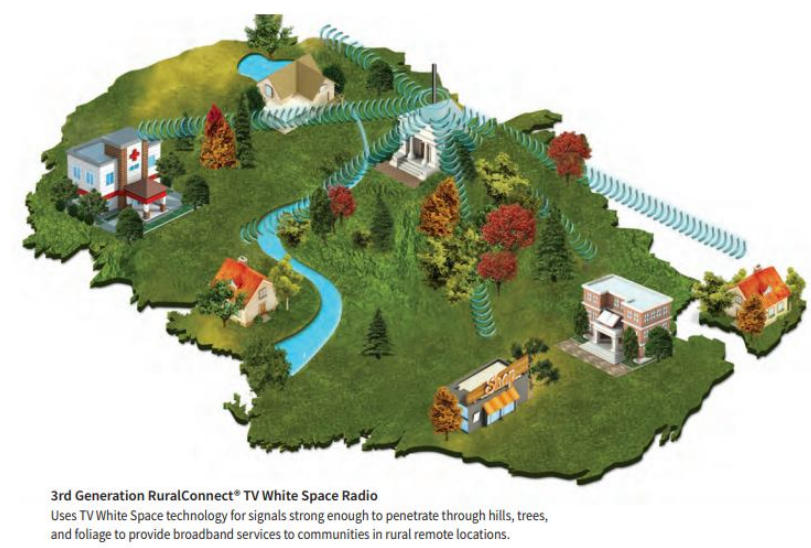

Figure 7: Carlson Wireless Rural Connect [16] NLOS solution

Carlson Wireless Infographic as seen in Figure 7 as an application scenario for connecting rural areas since TVWS provides an NLOS solution and can penetrate objects such as trees and hills. This solution can leverage data access for those in rural areas.

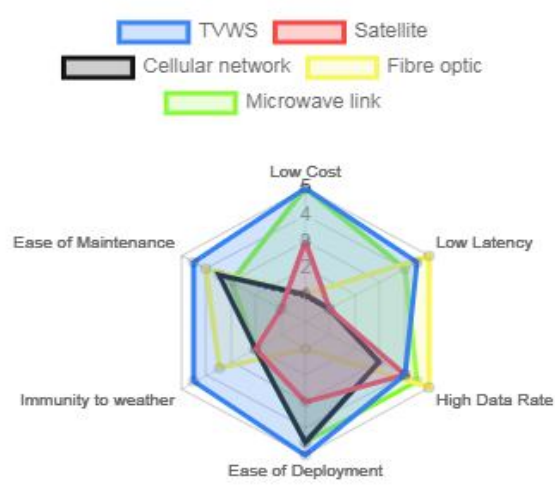

Figure 8: Whizpace Comparison of TV Whitespace [2]

Whizpace does a comparison with other telecommunication systems, as seen in figure 8 . TVWS has the advantage of most of the systems but is limited to regulations among countries. Hence, TVWS is most suitable in rural and remote areas to provide broadband access since remote areas are mostly free of TV broadcasting. This can be considered by ISPs to build a hybrid network using TVWS as the last-mile solution

These devices are not limited to rural broadband applications, there are a vast amount of cases for utilizing TVWS. Smart agriculture development, Smart Oil and Gas, disaster management, connecting schools and hospitals, Advanced metering infrastructure (AMI) [23] to name a few. 


\section{RELATED TECHNOLOGIES AND FURTHER STUDIES}

With the rising of TVWS technology, there are still even more ways on how to cut its drawbacks. Other technologies can be incorporated with the evolution of TVWS such as WATCH or Wi-Fi in active TV channel. This is a study and implementation by Xu Zhang [24], wherein they surveyed a population in a certain area where TV viewership is still low even at primetime. They came up with a solution that involves sensing of TV that is not tuned-in in a channel using smartphones as a mean for sensing the used spectrum in the area. Their design enables secondary transmission during active TV broadcasts and incorporates special techniques for cancellation of the use of the active channel of the active broadcast.

For the querying of devices, as mentioned in the previous sections, a device must access a WSDB periodically depending on regulation and follow the PAWS. To provide Quality of service (QOS) for SUs an Analytical hierarchy process (AHP) is proposed in combination with PAWS that can be found in [25]. This proposal gives a good channel selection technique so as to give priority to other users subsequently providing a good anti-interference scheme between TVWS users.

Software-defined radios (SDR) are also a trend to support cognitive radio [26]. SDRs are used that allow general telecommunication hardware to alter its protocols, coding, and modulation to match the preferred operation. One of the leading suppliers of these devices also for whitespace is the Saankhya Labs. This technology, if applied to TVWS technology will greatly increase its flexibility since operating in this system requires a system or a device that is flexible to different operating parameters.

Mandeep Ramdev and Rohit Bajaj [27] presents a solution for the coexistence of Long term evolution -licensed assisted access (LTE-LAA) and Wi-Fi. In the frequency band of $5 \mathrm{GHz}$ where these two technologies co-exist where one is licensed and one is unlicensed respectively using a Monte Carlo based method is used named as 3DMCAT. Configuration of the 3DMCAT can be applied also in TVWS to improve coexistence characteristics and power efficiency [28].

\section{CONCLUSION}

This paper gives an overview of TVWS technology and devices. These can be a way of how the ISPs or the government can bridge the gap of digital divide, connecting rural areas to enhance development and access to information. TVWS provides a great solution with only minimal deployment and wide coverage of area. These technologies can open a good discussion among regulatory boards of telecommunications in other countries that are planning to utilize the unused spectrum for efficient dynamic spectrum access. WSDs are already available in the market as applied, tested and approved by different regulatory board namely FCC and IDA. The study also sees potential gaps among WSDs. Flexibility of these devices to operate in other topologies is one of the gaps and can be improved using SDRs. They are also being restricted in which country they are being developed thus limiting them in such regulations of the country in TVWS usage. Lastly, the interoperability among the devices or the access also to WSDB can impose problems in implementing the technology.

\section{Acknowledgment}

De La Salle University is acknowledged for supporting this work.

\section{REFERENCES}

[1] F. C. Commission and others, "Second Report and Order and Memorandum Opinion and Order, in the matter of unlicensed operation in the TV broadcast bands (ET Docket No. 04-186) and additional spectrum for unlicensed devices below $900 \mathrm{MHz}$ and in the $3 \mathrm{GHz}$ band (ET Docket No. 02-380), FCC 08260." Nov, 2008.

[2] "TV White space | super wifi technology | Whizpace."

[3] L. Zhu, V. Chen, J. Malyar, S. Das, and P. McCann, "Protocol to access white-space (paws) databases," 2015.

[4] A. B. Flores, R. E. Guerra, E. W. Knightly, P. Ecclesine, and S. Pandey, "IEEE 802.11 af: A standard for TV white space spectrum sharing," IEEE Communications Magazine, vol. 51, no. 10, pp. 92100, 2013. https://doi.org/10.1109/MCOM.2013.6619571

[5] S. W. Oh, Y. Ma, M. H. Tao, and E. Peh, TV White Space: The First Step Towards Better Utilization of Frequency Spectrum. Wiley, 2016.

[6] "White Space Hunter - TVWS GLDB." .

[7] "Weightless-P Standard is Designed for High Performance, Low Power, 2-Way Communication for IoT - Weightless Management Ltd." 2015.

[8] "WhiteSpace Alliance - About Us." .

[9] S. Labs, "Meghdoot Base Station SLB802ODU Saankhya Labs - software defined radios (SDR)." .

[10] S. Labs, "Dhaval CPE Modem SLC802ODU Saankhya Labs - software defined radios (SDR)." .

[11] Datasheet, "Adaptrum-ACRS2-Client-Datasheet1017.pdf." 2017.

[12] Datasheet, "Adaptrum-ACRS2-B1000-Datasheet0717.pdf.” 2017.

[13] Datasheet, "Adaptrum-ACRS2-B2000-Datasheet0518.pdf." 2018.

[14] Datasheet, "6Harmonics GWS4000.” 2016.

[15] DataSheet, "KTS Wireless Agility WhiteSpace Radio." 2013.

[16] Datasheet, "RuralConnect-Gen3-ETSI-03-22-18Print-Book-r.pdf.” 2018.

[17] Datasheet, "RuralConnect-Gen3-US-03-28a-18-PrintBook-r.pdf." 2018. 
[18] DataSheet, "Redline-DS-Ellipse.pdf." 2016.

[19] DataSheet, "Aviacomm PB Template." 2019.

[20] Datasheet, "MSC_Raptor XR Domestic VHF-UH..." 2018.

[21] Whizpace, "tv white space equipment | Whizpace | Singapore.".

[22] "TV WhiteSpaces - Search Result.".

[23] "tv white space applications | Whizpace | Singapore."

[24] X. Zhang and E. W. Knightly, "WATCH: WiFi in active TV channels," IEEE Transactions on Cognitive Communications and Networking, vol. 2, no. 4, pp. 330-342, 2016.

https://doi.org/10.1109/TCCN.2016.2625330

[25] A. S. Makgamatha, T. Zuva, and M. T. Masonta, "Channel selection technique to satisfy secondary users quality of service (QoS) requirements in TV white space," in 2018 International Conference on Advances in Big Data, Computing and Data Communication Systems (icABCD), 2018, pp. 1-8. https://doi.org/10.1109/ICABCD.2018.8465133

[26] O. Holland, H. Bogucka, and A. Medeisis, Opportunistic spectrum sharing and white space access: The practical reality. John Wiley \& Sons, 2015.

https://doi.org/10.1002/9781119057246

[27] M. Singh Ramdev, "Comparative Analysis of LTELAA and Wi-Fi Systems in Various Domains," International Journal of Advanced Trends in Computer Science and Engineering, vol. 8, pp. 758763, 62019.

https://doi.org/10.30534/ijatcse/2019/66832019

[28] H. Chaurasiya and S. Ghosh, "Performance Evaluation of Energy-Efficient Cluster based Algorithms in Wireless Sensor Network," International Journal of Advanced Trends in Computer Science and Engineering, vol. 7, pp. 77-81, 102018. https://doi.org/10.30534/ijatcse/2018/03752018 